\title{
Percutaneous aortic valves: Effective in inoperable patients, what price in high-risk patients?
}

\author{
Lars G. Svensson, MD, PhD
}

The use of methods for insertion of percutaneous valves has increased more rapidly than anticipated, particularly in view of the fact that there were early problems with both clinical and animal research. ${ }^{1-7}$ Indeed, preliminary trials with the transapically inserted aortic valves were associated with a high risk of embolization. ${ }^{4}$ There were 3 likely reasons for this. (1) There was no calcification in the aortic valve to anchor the stent, (2) the juvenile animals had a pliable annulus, and (3) some of the earlier devices were covered with a smooth cloth. Furthermore, the transfemoral venous approach pioneered by Cribier and colleagues ${ }^{1}$ was associated with problems related to the complexity of the transseptal approach, which also required making the device snake through the left ventricle, resulting in both a high incidence of stroke and death. Nevertheless, the perseverance of Webb and associates ${ }^{2}$ resulted in the development of the retrograde transfemoral aortic approach, which has become the method of choice whereby $50 \%$ to two thirds of devices are inserted. At the same time, CoreValve, ${ }^{5,6}$ now owned by Medtronic (Minneapolis, Minn), developed a retrograde transfemoral approach that has also resulted in many devices being inserted. In total, some 15,000 devices have now been inserted in patients around the world.

For a valve procedure to be accepted into practice, 4 criteria are required: (1) Insertion is easy, (2) the procedure is safe, (3) the result has an acceptable effective orifice area, and (4) the long-term durability and survival is good. Research continues on whether the new percutaneous valves meet these criteria.

For the transapical approach, an anterior-lateral thoracotomy is made in the fifth or sixth intercostal space with or without a rib resection (Figure 1). Purse-string sutures are then placed in the left ventricular apex. At the same time, a transfemoral venous pacing wire is inserted, and a transarterial pigtail fed up into the aortic root. Next, a needle followed by a short guide wire is inserted in the left ventricle: The needle is removed, a size 14 sheath is inserted, the wire is removed, and a Berman balloon catheter under fluoroscopy is fed into

\footnotetext{
From the Aorta Center, Marfan and CTD Clinic, the Cleveland Clinic, Cleveland, Ohio.

Disclosures: Lars G. Svensson has nothing to disclose with regard to commercial support.

Received for publication April 28, 2010; accepted for publication July 12, 2010.

Address for reprints: Lars G. Svensson, MD, PhD, Cleveland Clinic, Department of Thoracic and Cardiovascular Surgery, 9500 Euclid Avenue, Cleveland, OH 44195 (E-mail: svenssl@ccf.org).

J Thorac Cardiovasc Surg 2010;140:S10-3

$0022-5223 / \$ 36.00$

Copyright (c) 2010 by The American Association for Thoracic Surgery doi:10.1016/j.jtcvs.2010.07.037
}

the left ventricle, and then across the aortic valve down to the renal arteries, using fluoroscopy for positioning. The extra stiff wire is fed through the Berman catheter down to the renal arteries (if it has not already been used for crossing the aortic arch). In some patients, the difficulty of negotiating the aortic arch may require the use of a Wooley wire to maneuver around the arch. At this stage, both the Berman balloon catheter and the $14 \mathrm{~F}$ sheath are removed, and the large-bore delivery introducer sheath is inserted into the left ventricular apex, enabling the dilator to be removed. A 3- to 5-cm balloon is then fed over the wire into the native aortic valve and, during rapid pacing, inflated to perform the valvuloplasty. Now, transesophageal echocardiography is used to check the result. The new stent valve is then mounted on a balloon in a loader, and the loader is connected to the end of the sheath and used for feeding the new device into the apex of the ventricle. Next, the device is pushed across the native valve and the pusher catheter is drawn back into the large-bore delivery sheath. After careful positioning of the valve using transesophageal echocardiography, flushing of the aortic root with contrast dye, and noting the positioning of the valve in relation to calcium in the root, rapid pacing is commenced (usually at 180 beats/min) and the patient's breath held. The valve is deployed by inflating the balloon. More recently, we have been deploying and inflating the balloon at a slower pace, which allows us to reposition the valve if there has been movement during the period of inflation. Thus, the valve can be positioned more "aortic" or "ventricular" during deployment to adjust for movement. Then, the balloon is then withdrawn into the sheath and positioning checked by transesophageal echo and fluoroscopy.

For the first 40 very high-risk patients undergoing this procedure in the United States during the feasibility trial, the mortality rate was $17 \%,{ }^{3}$ but in those patients who had a successful operation and insertion of the device, the effective orifice areas and reduction in gradients were impressive. No strokes occurred immediately after the procedure in patients who had a successful valve deployment.

The transfemoral retrograde arterial approach involves placing a transvenous wire for pacing and insertion of a transfemoral pigtail and then a large-bore sheath into the other femoral artery (Figure 2). The subsequent procedure of balloon valvuloplasty, followed by inflation of the balloon with the stent device, is similar to the transapical approach. In most patients, a femoral artery or vein cut-down is not needed. In the United States, the transfemoral aortic valve insertion feasibility trial ([Percutaneous Endovascular 


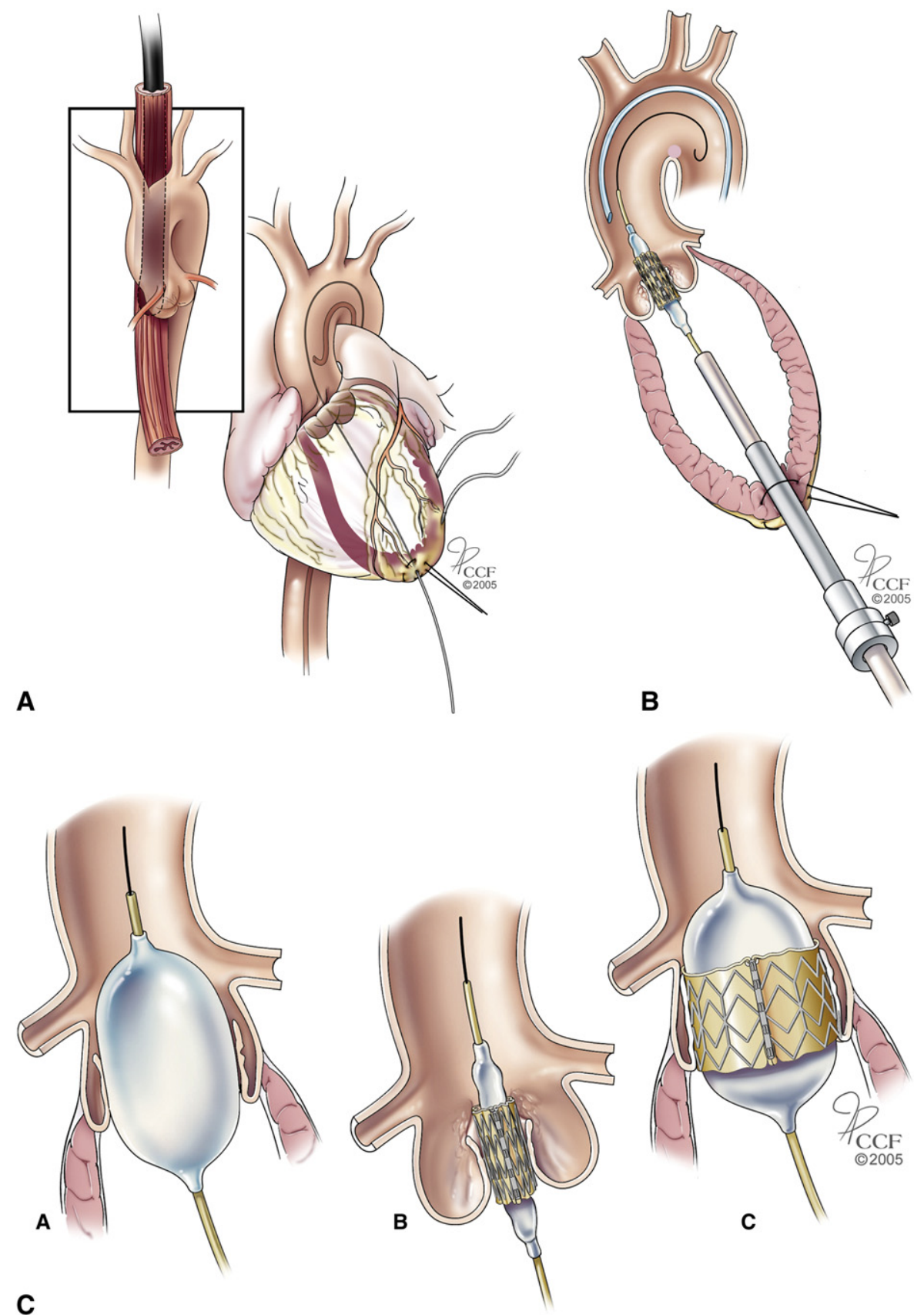

FIGURE 1. Steps in the insertion of a transapical aortic valve. A, Purse sting and transducer positioning. B, Apogeefig_2 Sheath and device insertion. C, Stent deployment, first balloon valvuloplasty, positioning device, and balloon inflation.

Implantation of Valves trial [REVIVAL]) results showed the risk of death was $7 \%$, the risk of stroke was $9 \%$, and the risk of vascular injury was $13 \%$.

After the feasibility trials, the Placement of Aortic Transcatheter Valves (PARTNER) randomized trial was commenced. In this study, the patients were randomized to group A (high-risk surgical, $\mathrm{N}=700$ ) or $\mathrm{B}$ (inoperable, $\mathrm{N}=358$ ). Group A patients were randomized to open surgery or device, inserted by the transfemoral approach if good access was present, or the transapical approach if femoral artery access was not possible. Group B patients were randomized to transfemoral insertion or best medical treatment. The entry criteria were strict, with all patients required to have a valve area less than $0.8 \mathrm{~cm}^{2}$ and, for group A, a Society of Thoracic Surgeons' score greater than $10 \%$. Eighty-seven percent of those receiving "best medical treatment" underwent valvuloplasty. Group B enrollment was completed by March 16, 2009, and group A enrollment was completed by August 28,2009 . The results of group B were reported September 28, 2010, and the results of group A are expected in March 

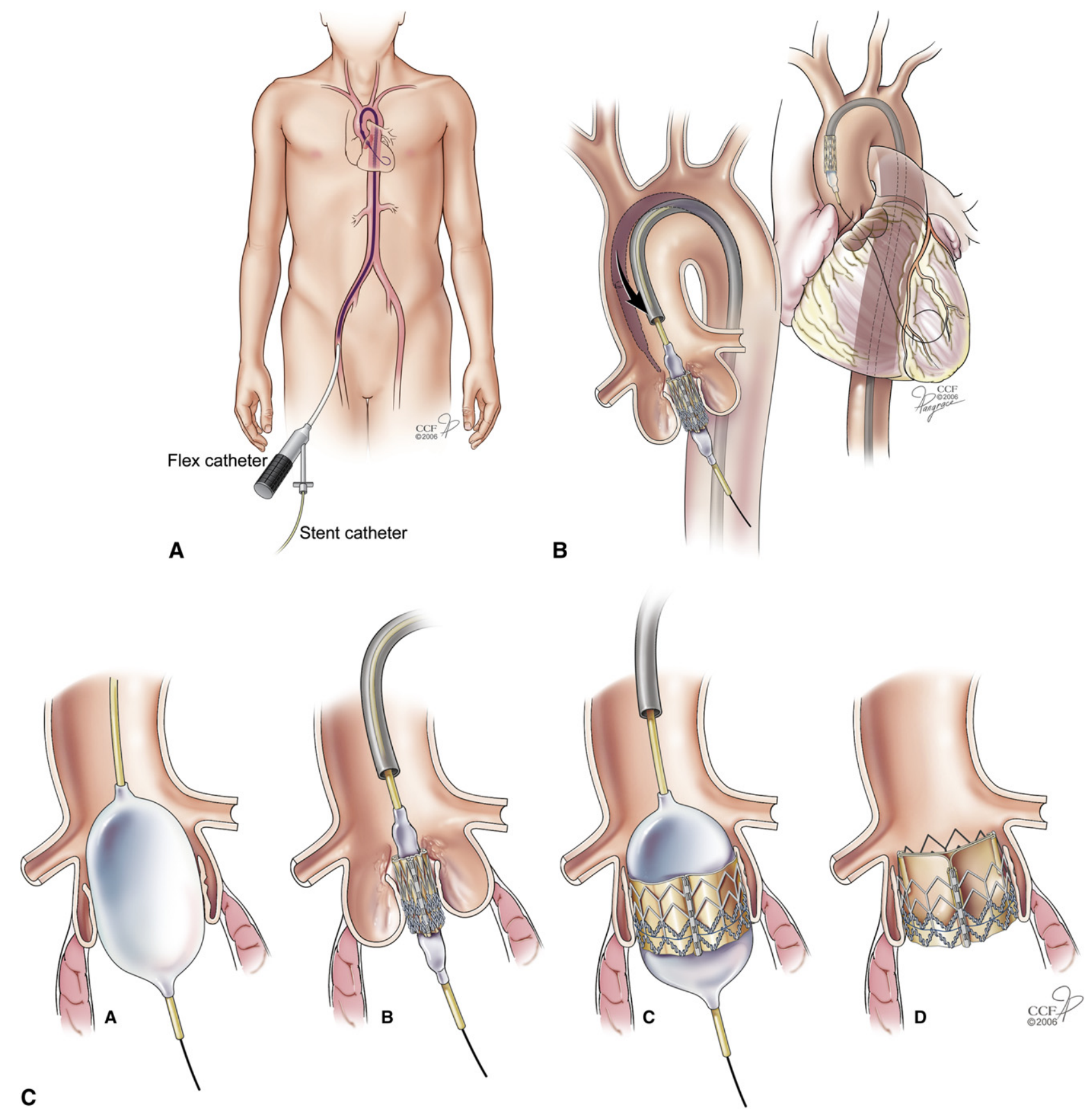

FIGURE 2. Steps in the insertion of a transfemoral arterial aortic valve. A, Flexible catheter introduction. B, Flexing catheter around the arch. C, Device deployment, first balloon valvuloplasty, device placement, balloon inflation with device, positioned new valve.

2011. In PARTNER B, patients treated with the device had a $6.4 \%$ 30-day procedure mortality and 5\% major stroke rate but at 2 years the survival was $67 \%$ better $(P<.0001)$. Meanwhile, continued access is allowed. PARTNER IIB commences later this year, and group A likely commences thereafter. The entry criteria will be somewhat modified, and access will be with a new smaller 18F device.

The CoreValve device (depending on Food and Drug Administration approval) will probably be inserted in patients in the United States in 2010 or 2011. A number of test sites have been approved by the sponsor, Medtronic. The sites include the primary investigator sites of Mt Sinai in New York and Beth Israel Deaconess in Boston.

\section{CONCLUSIONS}

Transapical and transarterial valve insertion approaches have become viable treatment options in high-risk and inoperable patients. Clearly, PARTNER B has shown 
significant improvement over medical treatment in inoperable patients but at the price of stroke. The PARTNER A trial outcomes will be watched with great interest because this is a comparison with surgery. The progress of trials using the CoreValve device has just been approved. Thus, although these new devices are easy to insert, safe in inoperable patients, and with equivalent hemodynamics to open valve replacement, the long-term durability is unknown and the price of insertion needs to be reduced.

\section{References}

1. Cribier A, Eltchaninoff H, Bash A, Borenstein N, Tron C, Bauer F, et al. Percutaneous transcatheter implantation of an aortic valve prosthesis for calcific aortic stenosis: first human case description. Circulation. 2002;106:3006-8.
2. Webb JG, Chandavimol M, Thompson CR, Ricci DR, Carere RG, Munt BI, et al Percutaneous aortic valve implantation retrograde from the femoral artery. Circulation. 2006;113:842-50

3. Svensson LG, Dewey T, Kapadia S, Roselli EE, Stewart A, Williams M, et al. United States feasibility study of transcatheter insertion of a stented aortic valve by the left ventricular apex. Ann Thorac Surg. 2008;86:46-55.

4. Dewey TM, Walther T, Doss M, Brown D, Ryan WH, Svensson L, et al. Transapical aortic valve implantation: an animal feasibility study. Ann Thorac Surg. 2006;82:110-6.

5. Laborde J, Borenstein N, Behr L, Farah B, Fajadet J. Percutaneous implantation of the CoreValve aortic valve prosthesis for patients presenting high risk for surgical valve replacement. EuroIntervention. 2006;1:472-4.

6. Grube E, Laborde JC, Gerckens U, Felderhoff T, Sauren B, Buellesfeld L, et al. Percutaneous implantation of the CoreValve self-expanding valve prosthesis in highrisk patients with aortic valve disease: the Siegburg first-in-man study. Circulation 2006;114:1616-24.

7. Kapadia SR, Svensson L, Tuzcu EM. Successful percutaneous management of left main trunk occlusion during percutaneous aortic valve replacement. Catheter Cardiovasc Interv. 2009;73:966-72. 